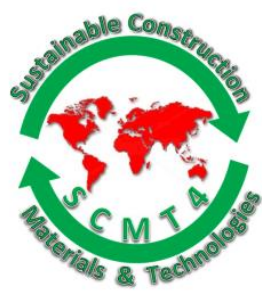

SCMT4

Las Vegas, USA, August7-11, 2016

\title{
Properties of Concrete Obtained from Existing Building Constructed in 1964
}

\author{
Hideo Araki ${ }^{1}$ \\ ${ }^{1}$ Hiroshima Institute of Technology - Saekiku Miyake 2-1-1, Hiroshima, Japan. \\ Email: <h.araki.k4@it-hiroshima.ac.jp >.
}

\begin{abstract}
The properties of old concrete obtained from existing buildings are important factors in the seismic evaluations of these buildings. However, these properties are sometimes different from the design performance in the structural drawing. The properties of concrete are investigated in existing buildings and are affected by deteriorations over long time periods, uncertainty of construction and several other important factors. 59 test specimens were manufactured from the concrete cylinders of an old reinforced concrete (RC) gymnasium planned for demolition. In this paper, the mechanical properties of concrete are discussed, and carbonation tests are performed. From the compressive tests using 34 test specimens, the compressive strengths were widely distributed. The lowest strength was less than half of the specified strength of $17.6 \mathrm{~N} / \mathrm{mm}^{2}$, although the average compressive strength of $17.3 \mathrm{~N} / \mathrm{mm}^{2}$ was almost the same as the specified strength. Based on the result of the componential analysis of the concrete it was found that the main factor influencing the strength was water/cement ratio. From splitting tests using 25 test specimens, the tensile strengths were distributed from $0.59 \mathrm{~N} / \mathrm{mm}^{2}$ to $2.03 \mathrm{~N} / \mathrm{mm}^{2}$. The modulus of elasticity was approximately 0.7 times of the estimated values by using the present equations. The carbonation rates of the concrete were greater than the estimated values.
\end{abstract}

\section{INTRODUCTION}

Seismic evaluations of existing reinforced concrete buildings have been extensive in Japan since the Kobe earthquake of 1995. It is reported that these seismic evaluations found many RC buildings had not been constructed according to the structural drawing, although the seismic evaluation was performed based on the structural drawing. In the present standard for seismic evaluation [JBDPA 2001], compressive tests using three concrete cylinders from each story of the building are required. Many RC buildings with very low strength concrete, i.e. less than half of the design concrete strength, were found. The mechanical properties of the concrete are one of the most important factors of the seismic performance of an existing building. For example, the maximum strength of the concrete is concerned with the shear strength of the columns, and modulus of elasticity is related to the bearing strength of the post-installed anchor bolts used in the retrofitting process. The modulus of elasticity, tensile strength and strain at the maximum strength were evaluated with the equations in the present RC standard [AIJ RC 1991 and AIJ Guideline 1999]. These equations were defined by the experimental test data of the concrete manufactured in the laboratory. Therefore, it is necessary to clarify the validity of those equations with the old concrete obtained from existing buildings. The author had the opportunity to obtain the old concrete when the existing building was demolished at 2014 . 


\section{OUTLINE OF INVESTIGATION}

Target bulding and test specimens. The target building in this study was a gymnasium constructed in 1964, as shown in figure 1 . This building located in a coastal area, consisted of two story RC frames with shear walls and a steel roof. The specified concrete strength in the structural draft was $17.6 \mathrm{~N} / \mathrm{mm}^{2}\left(180 \mathrm{~kg} / \mathrm{cm}^{2}\right)$. This building was planned for demolition based on the preliminary investigation because the obtained concrete was judged as low strength concrete of less than $13.5 \mathrm{~N} / \mathrm{mm}^{2}\left(13.5 \mathrm{~N} / \mathrm{mm}^{2}\right.$ is the recommended lower limit of concrete strength in the standard [JBDPA 2001]). In seismic evaluations, concrete cylinders used for the compressive tests are usually obtained from the non-structural members, for example, the wing wall or spandrel wall. This is because the work process of core boring from those members is relatively easy. However, it is reported that the concrete strength of those members is estimated to be lower than the concrete strength from the structural members; girders, columns and shear walls [Shimizu 2000]. Therefore, the concrete cylinders in this paper were obtained from structural members as shown in figure 2. The direction of core boring was orthogonal to the axis of the structural members. 19 concrete cylinders were obtained from all columns of the first story with the exception of one column and 4 columns of the second story. One column of the first story had already been demolished. 12 cylinders were also obtained from the girders of the first story in the short directions of the building shown in figure 3 . The length of the concrete cylinders obtained from the columns was $600 \mathrm{~mm} \sim 680 \mathrm{~mm}$ and those from the girders was $400 \mathrm{~mm}$. 50 test specimens from columns and 12 test specimens from the girders were manufactured from 31 concrete cylinders, for a total number of 62 test specimens, 37 test specimens were used for compressive tests and 25 test specimens were used for splitting tests.

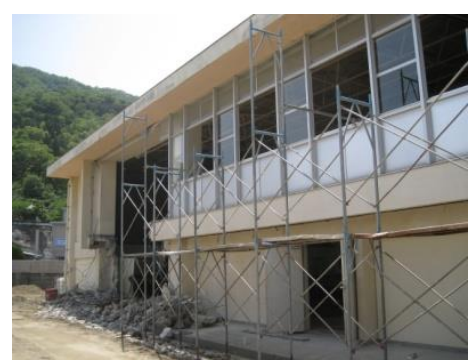

Fiure 1. Target Building

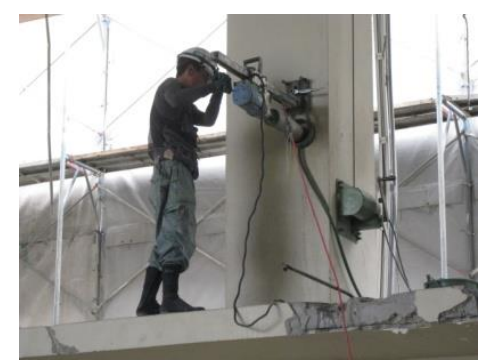

Figure 2. Core Boring(2F)

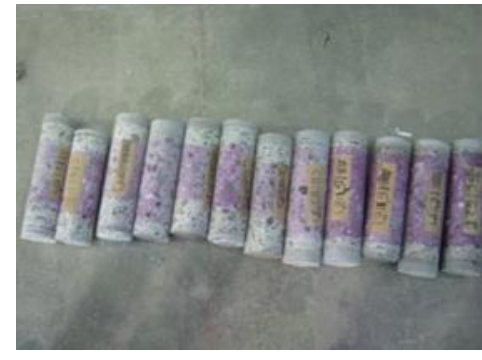

Figure 3. Concrete Cylinder

\section{Loading and measurement}

Compressive tests. The length (L) of the test specimens was $200 \mathrm{~mm}$ and the diameter (D) was $100 \mathrm{~mm}$, following the Japanese Industrial Standard [JIS A 1107 2002]. The loading and measurement system in the compressive tests is shown in figure 4 [JIS A 1108 2002]. Modification factors for concrete strength were used according to this standard, when the L/D ratio was less than two. The compressive force was increased monotonically in loading. The axial and transverse strains were monitored by displacement transducers in the compressometer and wire strain gauges. The measurement length in the compressometer was $100 \mathrm{~mm}$, and $60 \mathrm{~mm}$ strain gauges were used as shown in the Figure. The compressometer was effective in measuring the post peak stress strain-curve. Modulus of elasticity was obtained from the stress strain curve using Eq. (1), following [JIS A 1108 2002].

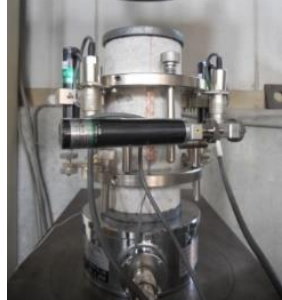

Figure 4. Compressive Test

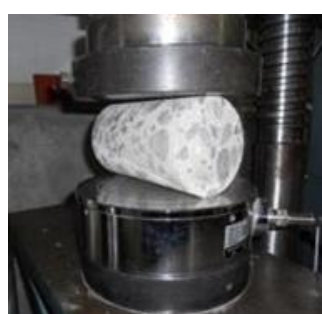

Figure 5. Splitting Tensile Test

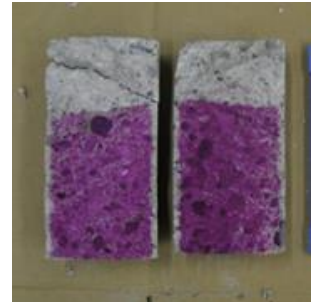

Figure 6. Carbonation Test 
$E_{c}=\frac{S_{1}-S_{2}}{\varepsilon_{1}-\varepsilon_{2}}$
$E_{C}:$ Modulus of elasticity $\left[\mathrm{N} / \mathrm{mm}^{2}\right]$
$S_{2}:$ Stress at strain $50 \times 10^{-6}\left[\mathrm{~N} / \mathrm{mm}^{2}\right]$
$\varepsilon_{2}:$ Strain $50 \times 10^{-6}$

\section{$S_{1}:$ Stress of $1 / 3$ maximum stress $\left[\mathrm{N} / \mathrm{mm}^{2}\right]$}

$\varepsilon_{1}:$ Strain at stress $S_{1}$

Splitting tests. The tensile stress of the concrete was obtained by a splitting test shown in figure 5 [JIS A 1113 2002]. Only the maximum load was measured. Tensile stress was calculated from the maximum load using Eq. (2). After the splitting test the carbonation tests were performed as shown in figure 6.

$$
\sigma_{s t}=\frac{2 P}{\pi \times D \times L}
$$
$\sigma_{s t}:$ Tensile stress $\left[\mathrm{N} / \mathrm{mm}^{2}\right]$
$D$ : Diameter of concrete cylinder [mm]
$P$ : Maximum load $[\mathrm{N}]$
$L$ : Length of concrete cylinder $[\mathrm{mm}]$

\section{INVESTIGATED RESULTS}

Test results. The results obtained from the compressive and splitting tests are summarized in Table 1 .

Table 1. Summary of Test Results

\begin{tabular}{|c|c|c|c|c|c|}
\hline Member & $\begin{array}{c}\text { Unit weight } \\
\gamma\left(\mathrm{kN} / \mathrm{m}^{3}\right)\end{array}$ & $\begin{array}{c}\text { Compressive } \\
\text { strength } \\
\sigma_{B}\left(\mathrm{~N} / \mathrm{mm}^{2}\right)\end{array}$ & $\begin{array}{c}\text { Modulus of } \\
\text { elasticity } \\
\mathrm{E}_{\mathrm{c}}\left(\mathrm{N} / \mathrm{mm}^{2}\right)\end{array}$ & $\begin{array}{c}\text { Strain at } \\
\text { compressive } \\
\text { strength } \varepsilon_{m}(\mu)\end{array}$ & $\begin{array}{c}\text { Tensile } \\
\text { strength } \\
\sigma_{s t}\left(\mathrm{~N} / \mathrm{mm}^{2}\right)\end{array}$ \\
\hline \hline Column & $21.9(0.37)^{*}$ & $18.1(4.40)$ & $14.2(3.48)$ & $2910(570)$ & $1.23(0.35)$ \\
\hline Beam & $21.7(0.29)$ & $14.1(3.78)$ & $12.3(2.57)$ & $3165(639)$ & $1.56(-)$ \\
\hline All member & $21.9(0.37)$ & $16.9(4.59)$ & $13.8(3.29)$ & $2985(592)$ & $1.24(0.35)$ \\
\hline
\end{tabular}

* Standard deviation

Unit weight. The unit weight was obtained by measuring the weight and volume of each test specimen based on the standard [JIS A 1107 2002]. The average unit weight of 62 test specimens was approximately $22 \mathrm{kN} / \mathrm{m}^{3}$ while the unit weight recommended in the standard [AIJ RC 1991] is $23 \mathrm{kN} / \mathrm{m}^{3}$ for a compressive strength less than $36 \mathrm{~N} / \mathrm{mm}^{2}$. Standard deviations of 0.37 and 0.29 in both members were very small.

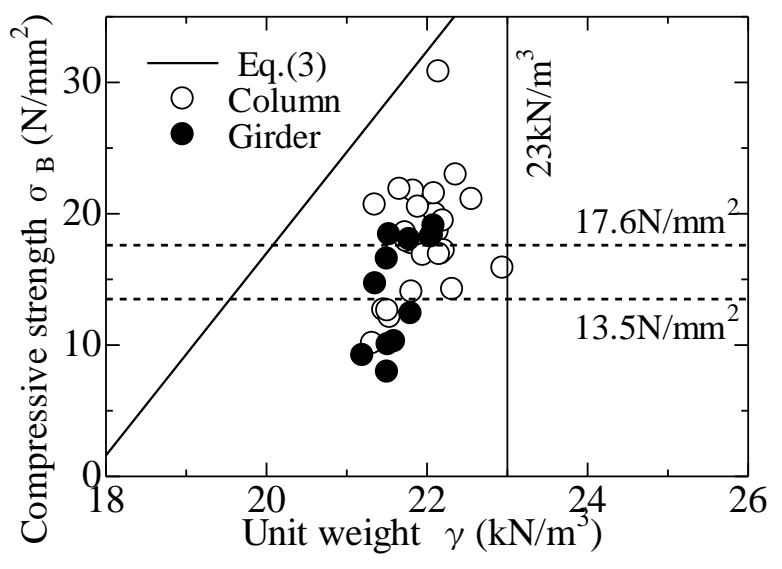

Figure 7. Unit Weight

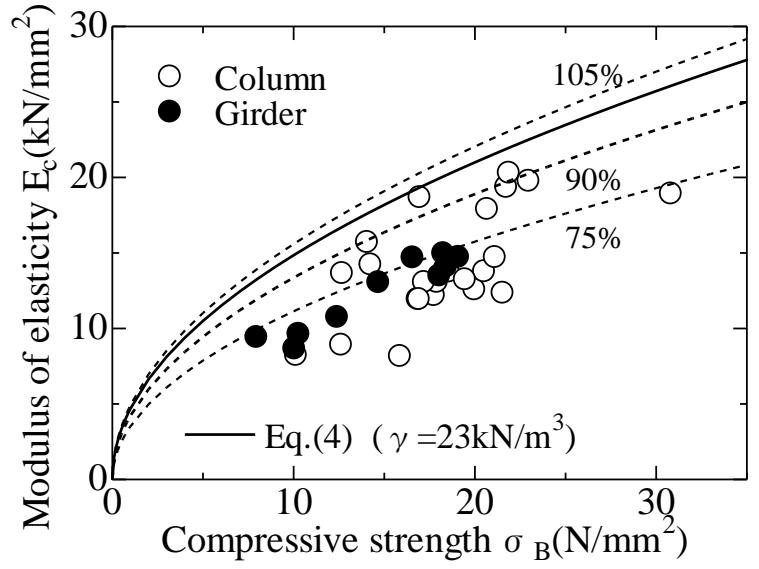

Figure 8. Modulus of Elasticity 
Compressive strength. The compressive strengths of both members were distributed in a wide range from $7.96 \mathrm{~N} / \mathrm{mm}^{2}$ to $30.8 \mathrm{~N} / \mathrm{mm}^{2}$. The average values of the columns in the first story and the second story are $18.4 \mathrm{~N} / \mathrm{mm}^{2}$ and $17.0 \mathrm{~N} / \mathrm{mm}^{2}$ respectively and they are nearly equal to the specified concrete strength $17.6 \mathrm{~N} / \mathrm{mm}^{2}$. Because the standard deviation in each story's columns is approximately the same, the test results of both story's columns will be combined in a future discussion. On the other hand, the compressive strengths of the girders were distributed from $7.96 \mathrm{~N} / \mathrm{mm}^{2}$ to $19.1 \mathrm{~N} / \mathrm{mm}^{2}$ and the average value was $14.1 \mathrm{~N} / \mathrm{mm}^{2}$, which is lower than the specified concrete strength. $49 \%$ of the test specimens had a compressive strength less than the specified strength $17.6 \mathrm{~N} / \mathrm{mm}^{2}$ in the structural drawing, and $24 \%$ of the test specimens had a compressive strength less than the lower limit of $13.5 \mathrm{~N} / \mathrm{mm}^{2}$ concrete strength in the standard [JBDPA 2001]. It is presumed that some kind of problem occurred at the construction site during construction. The relationship between the unit weight and the compressive strength are shown in figure 7. In a previous study, using 306 concrete cylinders from existing school buildings, Eq. (3) was proposed [Shimizu 2000]. Compressive strengths in this study were not consistent with the estimated values.

$$
\begin{aligned}
& \sigma_{B}=7.7 \times \gamma-137 \\
& \sigma_{B}: \text { Compressive strength }\left[\mathrm{N} / \mathrm{mm}^{2}\right] \\
& \gamma: \text { Unit weight }\left[\mathrm{kN} / \mathrm{m}^{3}\right]
\end{aligned}
$$

\section{Modulus of elasticity}

The modulus of elasticity was obtained by Eq. (1). The strain measured by the compressometer was used in the calculation, and strain measured by the strain gauge was used as the auxiliary. The obtained modulus of elasticity was distributed in the range of $8.0 \mathrm{kN} / \mathrm{mm}^{2}$ to $20.3 \mathrm{kN} / \mathrm{mm}^{2}$ and the average value of all members was $13.8 \mathrm{kN} / \mathrm{mm}^{2}$. The average value of the girders was $12.3 \mathrm{~N} / \mathrm{mm}^{2}$, which was lower than that of the column at $14.2 \mathrm{kN} / \mathrm{mm}^{2}$, although the standard deviation of the column was greater than that of the girders. The relationship between the modulus of elasticity and the compressive strength is shown in figure 8. The modulus of elasticity estimated by Eq. (4) using compressive strength and unit weight $23 \mathrm{kN} / \mathrm{m}^{3}$ [AIJ RC 1991] is inserted into the figure. It is known that the modulus of elasticity is affected by concrete strength, age of curing, aggregate, quality of cement, and dimensions of the specimen. The original equation used to estimate modulus of elasticity, using compressive strength and unit weight of the concrete, was empirically derived [Pauw 1960].

$$
E_{c}=21 \times\left(\frac{\gamma}{23}\right)^{1.5} \times\left(\frac{\sigma_{B}}{20}\right)^{0.5}
$$
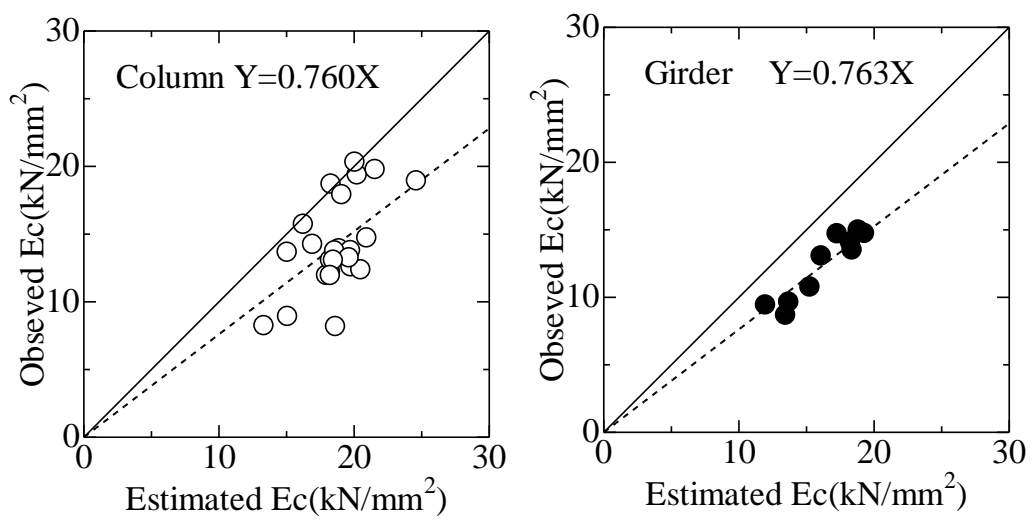

Figure 9. Comparisons between Observed and Estimated Modulus of Elasticity 
The observed modulus of elasticity was almost lower than the estimated values of Eq. (3) although the obtained modulus of elasticity increased when the compressive strength increased. It was reported that the observed modulus of elasticity was distributed in $90 \% \pm 15 \%$ of the estimated values in a previous study [Masuda 1982]. The number of observed values in this paper were out of the range proposed by Masuda. The previous study also reported that the modulus of elasticity of the concrete from the existing RC buildings constructed many years ago is lower than the estimated values [Araki 2010, 2014]. The apparent reason of the underestimation is not clear, however it is thought that modulus of elasticity was affected by creep phenomena or by deterioration from long term use. In the retrofitting process of the existing RC building, it is necessary to re-evaluate the present equation because the modulus of elasticity of the concrete is strongly related to the seismic performance of those buildings. The modulus of elasticity estimated by Eq. (3) using the corresponding unit wight and compressive strength are compared with the observed modulus of elasticity shown in figure 9. The regression lines by the least squares method are inserted in the figures. The ratios of the observed values to the estimated values in both members are approximately $76 \%$, which are near the lower limit proposed by Masuda.

Tensile strength. Research on the tensile strength of concrete from existing buildings is not so prevalent. In this paper, in order to clarify the relationship between the tensile strength and the compressive strength, test specimens for the splitting test and the compressive test were manufactured from one concrete cylinder. Most of the test specimens were manufactured from the concrete cylinders extracted from the columns, with the lengths of those cylinders being more than $600 \mathrm{~mm}$. One set of test specimens was manufactured from a cylinder extracted from a girder. The tensile strengths were distributed in the range of $0.59 \mathrm{~N} / \mathrm{mm}^{2}$ to $2.03 \mathrm{~N} / \mathrm{mm}^{2}$ and the average value of all members was $1.24 \mathrm{~N} / \mathrm{mm}^{2}$ as shown in Table 1 . The ratio of the average tensile strength to the average compressive strength was 13.6, and that was consistent with the result in the previous study. The relationship between the tensile strength and the corresponding compressive strength is shown in figure 10. The equations for tensile strength recommended in the standard [AIJ 1999] and [JSCE 2007] is inserted into the figure.

$$
\begin{aligned}
\sigma_{s t} & =0.33 \times\left(\sigma_{B}\right)^{0.5} \quad \text { AIJ } \\
\sigma_{s t} & =0.23 \times\left(\sigma_{B}\right)^{0.67} \quad \text { JSCE } \\
\sigma_{s t} & : \text { Tensile strength }\left[\mathrm{N} / \mathrm{mm}^{2}\right]
\end{aligned}
$$

Most of the observed tensile strengths were lower than the estimated values. Comparisons between the observed and the estimated tensile strength are shown in figure 11. The regression lines by the least squares method are inserted in the figures. The ratios of those values by both equations were 0.86 and 0.76 respectively.

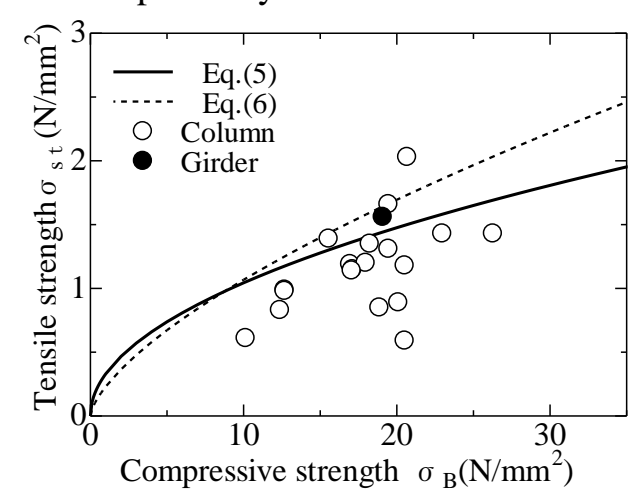

Figure 10. Tensile strength
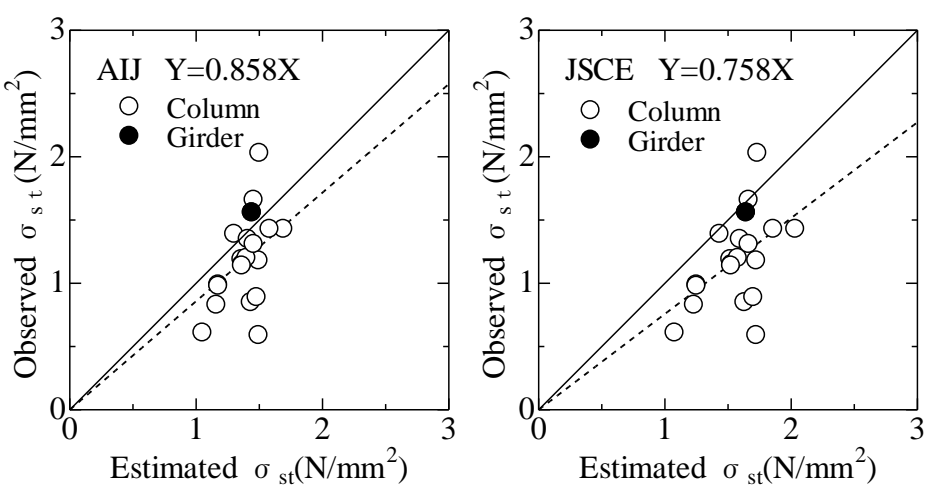

Figure 11. Comparison between estimated and observed tensile strength 
Strain at compressive strength. The strain at the maximum compressive strength in the stress strain curves were distributed in the wide range of $2060 \mu$ to $4343 \mu$. The average value is approximately $3000 \mu$ as shown in Table 1. The relationships between the strain at the compressive strength and the compressive strength are shown in figure 12. Some equations for the strain at compressive strength have been previously proposed [Popovics 1973, Murakami 2000, Muguruma 1980 and Shah 1983]. These equations are inserted into the figure. In the proposed equations, except for Murakami, the strain at compressive strength increased when the compressive strength increased. Conversely, the observed strain had a tendency to decrease when the compressive strength increased in the same way as the equation proposed by Murakami. The observed values were greater than those proposed by Eq.(8).

$$
\begin{array}{lrl}
\text { Popovics } & \varepsilon_{m} & =767 \times \sqrt[4]{\sigma_{B}} \\
\text { Murakami } & \varepsilon_{m} & =\sigma_{B} \times 10^{3} /\left(E_{c}(1-1 / n)\right) \\
& n=\exp \left(0.0256 \sigma_{B}\right) \\
& & \\
\text { Muguruma } & \varepsilon_{m} & =1299+13.3 \times \sigma_{B} \\
\text { Shah } & \varepsilon_{m} & =1950+14.9 \times \sigma_{B}
\end{array}
$$

$\varepsilon_{m}:$ Strain at the compressive strength $[\mu]$

Equation (11) for the stress strain curve in compression was proposed by Popovics, including the experimental factor $n$.

$$
\sigma=\sigma_{B} \times \frac{\varepsilon}{\varepsilon_{m}} \times \frac{n}{n-1+\left(\varepsilon / \varepsilon_{m}\right)^{n}}
$$

Murakami modified the experimental factor $n$ as Eq. (12) using the compressive stress, modulus of elasticity and strain at the compressive strength.

$$
n=\frac{1}{1-\sigma_{B} /\left(E_{c} \times \varepsilon_{m}\right)}
$$
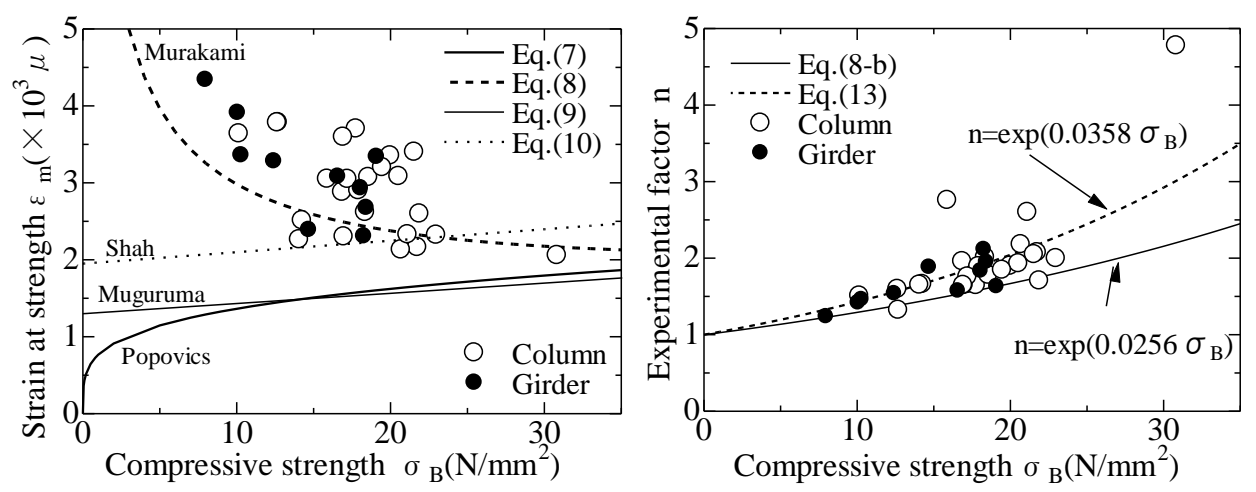

Figure 12. Strain at Maximum Strength Figure 13. Experimental Factor $n$

Based on the regression analysis using the data of the normal strength concrete, Eq. (8-b) was proposed as the experimental factor $n$. The experimental factor $n$ of the data in this study was estimated by Eq. (12) as shown in figure 13. Eq. (13) for the experimental factor $n$ is proposed from regression analysis using the experimental data in this study. 
Using Eq. (8-a) and Eq.(13) with the obtained compressive strength, the strain at the compressive strength could be estimated. The modulus of elasticity by Eq.(14) is proposed considering the ratio between the observed values and the estimated values $76 \%$ as shown in figure 9. The ratio of those values as shown in figure 14 was approximately 1.08 from the regression analysis. A significant difference was not observed in the members.

$$
E_{c}=16 \times\left(\frac{\gamma}{23}\right)^{1.5} \times\left(\frac{\sigma_{B}}{20}\right)^{0.5}
$$
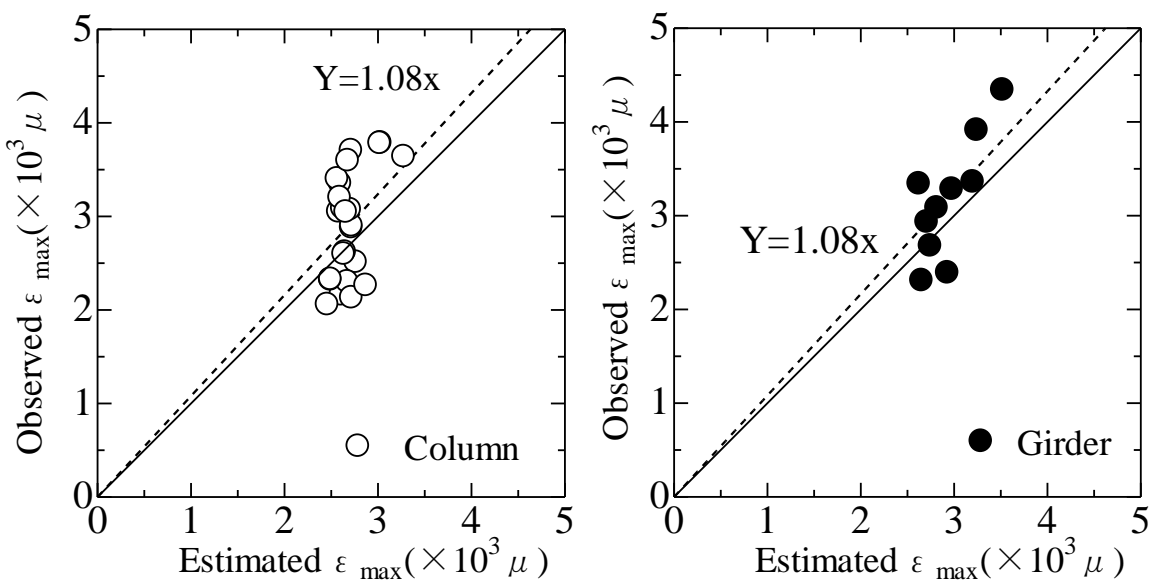

Figure 14. Comparisons between Observed and Estimated Strain at Compressive Strength

Stress strain curve. Stress strain curves were predicted using Eq. (11) proposed by Popovics, with the two experimentally obtained data in the study; the compressive stress and the unit weight. Comparisons between the observed and estimated stress strain curves are illustrated in figure 15. The strains measured by the compressometer were used in the comparisons. The stress strain curves were chosen in the range of the compressive stress from $20 \mathrm{~N} / \mathrm{mm}^{2}$ to less than $10 \mathrm{~N} / \mathrm{mm}^{2}$ from the space limitation.
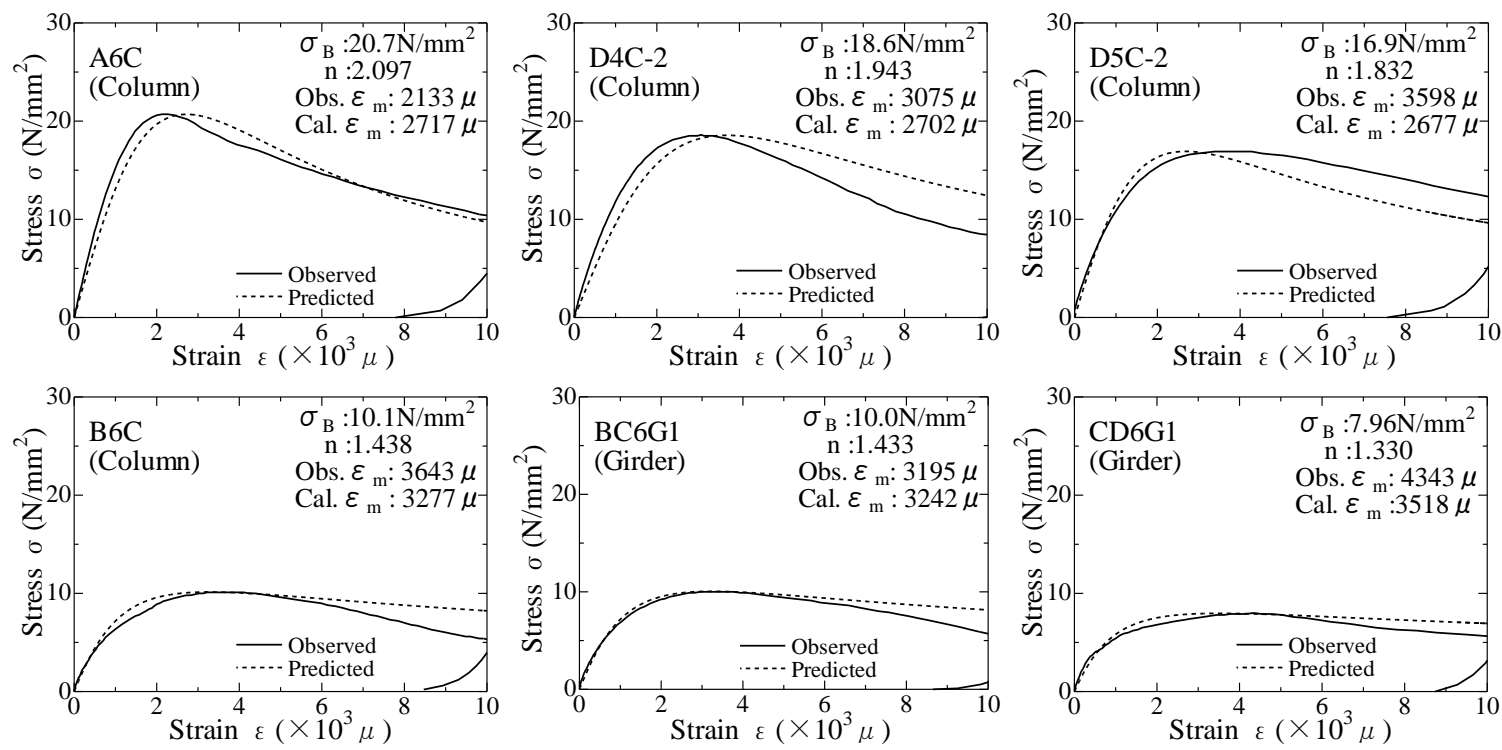

Figure 15. Comparison between Observed and Predicted Stress Strain Curves 
The observed compressive stress $\sigma_{\mathrm{B}}$, the experimental factor $n$, the observed strain Obs. $\varepsilon_{m}$ and the estimated strain Cal. $\varepsilon_{m}$ are inserted in the figure. While the compressive strength was greater than $17 \mathrm{~N} / \mathrm{mm}^{2}$ it was difficult to predict the curves after the post peaks. When the compressive strength was low, the outline of the stress strain curves could be predicted from the initial stage to the large strain $6000 \mu$. The degradation after the post peak was consistent with that of the low strength concrete manufactured in the laboratory [Tanigichi 2008].

Carbonation rate. After boring of the concrete cylinders, the carbonation depths were measured using Phenolphthalein Solution $(10 \mathrm{~g} / l)$. Maximum carbonation depths of the concrete of the building inside and outside were $86 \mathrm{~mm}$ and $76 \mathrm{~mm}$ respectively and the average values were $26 \mathrm{~mm} 36 \mathrm{~mm}$. Carbonation locally reached the concrete core in the stirrups. Several kinds of finishing materials were used in this building; mortar, stucco, lithin spraying and exposed concrete. It is said that the carbonation depth depends on the time elapsed after construction of building, as shown in Eq. (15). A factor of carbonation rate $A$ in Eq. (16) is recommended for the concrete after standard curing in the specification [JASS5 2009].

$$
\begin{aligned}
C= & A \sqrt{t} \\
A & =23.8(1 / \sqrt{f}-0.13) \\
& C: \text { Carbonation depth }[\mathrm{mm}] \\
& A: \text { Factor of carbonation rate }
\end{aligned}
$$

$t$ : Elapsed year after construction of building [year] $f$ : Specified concrete strength $\left[\mathrm{N} / \mathrm{mm}^{2}\right]$

The carbonation depth of the building estimated by Eq. (15) and Eq. (16) using the specified concrete strength $17.6 \mathrm{~N} / \mathrm{mm}^{2}$ was $18 \mathrm{~mm}$. The observed carbonation depths were much greater than the estimated value. The relationship between the factor of carbonation rate estimated by Eq. (16) and the compressive strength is shown in figure 16. The carbonation rate recommended in the standard [JASS5 2009] was also inserted in the figure. The observed values were greater than the estimated values regardless of whether the sample was from the inside or outside of the building. The relationship between the carbonation depth and the depth of the finishing material are shown in figure 17. A strong correlation of the carbonation to the depth of finishing material was not observed.

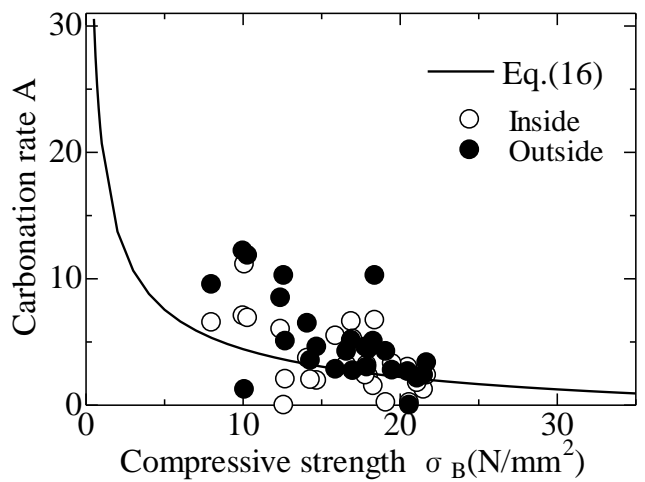

Figure 16. Carbonation Rate

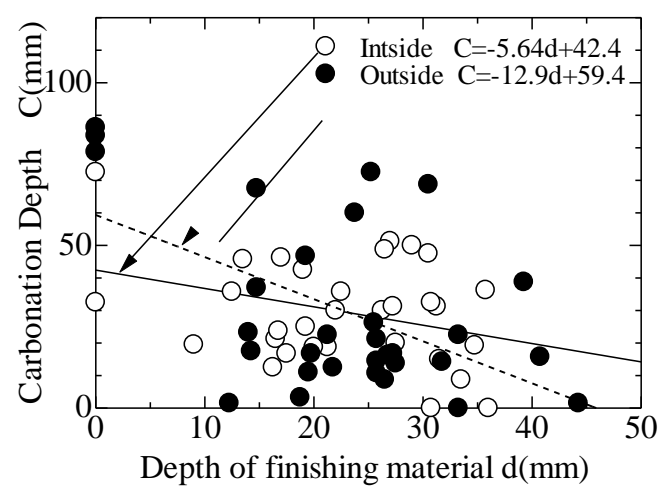

Figure 17. Carbonation Depth

\section{Componential analysis of concrete}

In order to investigate the reason that the compressive strengths were distributed in the wide range, the mix properties of the concrete were estimated by the method recommended by Japan Cement Association. After the four test specimens were pulverized the amount of water was estimated by heating the powder of the concrete. The amount of cement and aggregate were measured by dissolving the crushed concrete 
with hydrochloric acid. The test results are summarized in Table 2. The water cement ratios of low strength concrete less than $10 \mathrm{~N} / \mathrm{mm}^{2}$ were more than $100 \%$. Those of normal strength concrete were less than $80 \%$, which was ordinary water cement ratio. From the results of analysis, it is presumed that poor quality cement was used or a large amount of water was added at the time of construction.

Table 2. Estimated Mix Properties

\begin{tabular}{|c|c|c|c|c|c|}
\hline \multirow{2}{*}{$\begin{array}{c}\text { Test } \\
\text { specimen }\end{array}$} & \multirow{2}{*}{$\begin{array}{c}\text { Compressive } \\
\text { strength }\left(\mathrm{N} / \mathrm{mm}^{2}\right)\end{array}$} & \multicolumn{3}{|c|}{ Unit weight $\left(\mathrm{kg} / \mathrm{m}^{3}\right)$} & \multirow{2}{*}{$\begin{array}{l}\text { Water cement } \\
\text { ratio }(\%)\end{array}$} \\
\hline & & Cement & Water & Aggregate & \\
\hline CD6G1 & 7.96 & 172 & 195 & 1924 & 113 \\
\hline AB6G1 & 9.24 & 168 & 210 & 1898 & 125 \\
\hline B1C & 23.0 & 227 & 177 & 1939 & 78 \\
\hline A4C2 & 30.8 & 220 & 156 & 1942 & 71 \\
\hline
\end{tabular}

\section{CONCLUSION}

The following conclusions can be made:

- Compressive strengths were distributed in the very wide range of less than $10 \mathrm{~N} / \mathrm{mm}^{2}$ to more than $30 \mathrm{~N} / \mathrm{mm}^{2}$, although the specified concrete strength was $17.6 \mathrm{~N} / \mathrm{mm}^{2}$.

- Modulus of elasticity was less than the estimated value by the equation recommended by the AIJ. The ratio of the observed and estimated values was approximately $76 \%$. Considering the reported results in the previous study, it is necessary to improve the equation used in the seismic evaluation for the existing buildings.

- Tensile strengths were also distributed across a wide range. Most of the observed values were less than the estimated values.

- Strain at the maximum compressive strength decreased when the compressive strength increased. Based on the derived experimental factor $n$, the strain at the maximum strength can be estimated by the equation of [Murakami 2000]. The stress strain curves of concrete were predicted by the modified equation of [Popovics 1973]. The degradation after the post peak was consistent with that of the low strength concrete manufacture in the laboratory.

- From the estimated water cement ratio it is presumed that the low quality of cement were used or a large amount of water was added at the construction site.

\section{ACKNOWLEDGEMENTS}

This research has been supported by the Japan Ministry of Education, Culture, Sports, Science and Technology under Grant-in-aid No.25289190 and Chugoku Kensetsu Kosai-kai. The author appreciates the cooperation of Kure city in Hiroshima prefecture when collecting concrete cylinders from the gymnasium. The author would like to thank the staff and students of Hiroshima Institute of Technology.

\section{REFERENCES}

AIJ RC (1991). "Standard for Structural Calculation of Reinforced Concrete Structures" Architectural Institute of Japan

AIJ Guideline (1999). "Design Guideline for Earthquake Resistant Reinforced Concrete Buildings Based on Inelastic Displacement Concept" Architectural Institute of Japan 
Araki, H. and Yasojima A. (2010). "Mechanical Properties of Low Strength Concrete, $3^{\text {rd }}$ fib International Congress, Washington

Araki, H. and Hoshikawa T. (2014). "Mechanical Properties of Concrete Obtained from Existing Buildings; The $37^{\text {th }}$ IABSE Symposium, Spain, Madrid

JASS5 (2009). "Japanese Architectural Standard Specification JASS5 Reinforced Concrete Work", Architectural Institute of Japan

JBDPA (2001). "Standard for Seismic Evaluation of Existing Reinforced Concrete Building" Japan Building Disaster Prevention Association

JISA 1107 (2009). "Method of sampling and testing for compressive strength of drilled cores of concrete", Japan Industrial Standard

JISA 1108 (2009). "Method of test for compressive strength of concrete", Japan Industrial Standard

JISA 1113 (2009). "Method of test for splitting tensile strength of concrete", Japan Industrial Standard

JSCE (2007). "Standard Specifications for Concrete structure-Design-, Japan Society of Civil Engineers

Masuda, M., Tomosawa, F., and Yajima Y. (1982). "Concrete Quality in Existing reinforced Concrete Building Part 2 Concrete qualities by Element of Building and by Stories, Transactions of the Architectural Institute of Japan, No.317,pp.155-163,.

Muguruma, M., Watanabe, F., Tanaka, H., and Katsuta, S. (1980). "Improving the Flexural Ductility of Prestressed Concrete Beam by Lateral Hoop Reinforcement "Proceedings of the Japan Concrete Institute, Vol.2, No.2, pp.377-380

Murakami, K. (2000). "A Consideration on Calculation of Ultimate Shear Strength of Reinforced Concrete Beam”, Journal of Structural and Construction Engineering, Transaction of Architectural Institute of Japan, No. 533, pp. 143-150

Pauw, A. (1960). "Static Modulus of Elasticity of Concrete Affected by Density", Journal of American Concrete Institute, pp.679- 687, Dec.

Popovics, S., (1973). "A Numerical Approach to the Complete Stress - Strain Curve of Concrete," Cement and Concrete Research, Vol.3, pp.583-599,

Shah, S.P., Fafitis, A., and Arnold, R. (1983). "Cyclic Loading of Spirally Reinforced Concrete", ASCE, pp. $1695-1710$

Shimizu, Y., Hirosawa, M., Suzuki, K. and Sakamaki, K. (2000). "Seismic Performance of Existing School Buildings in A city Part 2 Property of Concrete", Annual Convention of Architectural Institute of Japan, pp.279-280

Taniguchi, H., Yasojima, A. and Araki, H. (2008). " Seismic Performance of Reinforced Concrete Beams with Low Strength Concrete", The $14^{\text {th }}$ World Conference on Earthquake Engineering, Paper ID0503-0034 